\title{
RICINUS OP DE BOVENWINDSCHE EILANDEN ${ }^{1}$ ) \\ DOOR
}

IR. W. SPOON

In 1939 is op de tot het Gouvernement Curaçao behoorende Bovenwindsche eilanden St. Eustatius, Saba en St. Maarten belangstelling ontstaan voor de winning van ricinusboonen, de zaden van wat de bevolking dier eilanden noemt de c a s t o r o i 1 p 1 a $\mathrm{n} \mathrm{t}^{2}$ ), wetenschappelijk bekend als Ricinus communis LINN. De plant, die lang geleden ingevoerd moet zijn en er goed wil gedijen, groeit er thans in het wild. Er is trouwens ook van andere zijde wel medegedeeld ${ }^{3}$ ), dat het klimaat op de Antillen voor de ricinuscultuur geschikt is, met name worden daarbij Guadeloupe en Jamaica ${ }^{4}$ ) (uit de reeks der Kleine resp. Groote Antillen) genoemd.

Die belangstelling hield verband met de pogingen van het Gouvernement om de bevolking der drie eilanden te brengen tot ruimere voortbrenging van eenvoudige gewassen uit den kleinen land- en tuinbouw ${ }^{5}$ ), in de eerste plaats voor de eigen voeding, doch daarnevens voor uitvoer naar de eilanden Curaçao en Aruba, alwaar door de vestiging van omvangrijke petroleumverwerkende industrieën groote vraag naar groente, fruit e.d. bestaat. Tot dat doel heeft het Gouvernement zoowel op St. Maarten als op St. Eustatius een proeftuin ingericht.

1) Tevens Bericht van de Afdeeling Handelsmuseum van het Koloniaal Instituut, no. 206.

$\left.{ }^{2}\right)$ Encyclopaedie van Nederlandsch West-Indië, 609 ('s-Gravenhage/Leiden 1914-'17).

s) Zie b.v. H. Grunwald, Rizinus, die Rizinuskultur, die Herstellung und Verwendung des Rizinusöles, 42 en 46 (Beiheft Tropenpflanzer Dec. 1930).

4) Zie b.v. H. C. Miller, Castor Oil, J. Jamaica Agr. Soc. 43, 25 (1939).

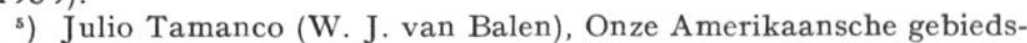
deelen, 83 (Utrecht, 1941) en van denzelfden auteur, Zes Nederlandse Antillen, 89 (Deventer 1941). 
Eenige malen (te beginnen met April 1939) heeft het Departement Accountantsdienst, Sociale en Economische Zaken te Willemstad, Curaçao, monsterzendingen van ricinusboonen en -olie, gewonnen op de Bovenwindsche eilanden, aan de Afdeeling Handelsmuseum van het Koloniaal Instituut ter beoordeeling voorgelegd. Rapporten zijn daarover opgezonden, de oorlog heeft het overleg echter ontijdig ten einde gebracht. Toch leek het ons raadzaam hier een en ander van de resultaten te vertellen, al is dan ook het vraagstuk niet aan alle kanten bekeken kunnen worden.

In de beoordeeling van de uit Willemstad ontvangen zaadmonsters (4 in totaal) hebben wij ter vergelijking eenige in onze verzamelingen aanwezige monsters van andere herkomst betrokken. Behalve enkele uiterlijke kenmerken, is in het scheikundig laboratorium van de Afdeeling Handelsmuseum van alle monsters het oliegehalte bepaald en in de verkregen olie het zuurgetal en het acetylgetal. De uitkomsten zijn in bijgaande tabel (blz. 227) bijeengebracht, aan de hand waarvan het volgende opgemerkt kan worden.

Het uiterlijk der boonen was binnen elk monster uniform, hetgeen er op wijst, dat de in het wild voorkomende complexen toch nog telkenmale één type van de plant vormen. De afmetingen van de boonen laten zich het gemakkelijkst aan de hand van het duizend-korrelgewicht bespreken. De vier monsters van andere herkomst blijken alle uit grootere boonen te bestaan dan de monsters van de Bovenwindsche eilanden, de laatstgenoemde moeten stuk voor stuk wel als zeer klein betiteld worden. De beteekenis van de stukgrootte der boonen blijkt bij de verwerking; ze bestaan namelijk voor ongeveer een kwart van het gewicht uit schil of zaadhuid, driekwart wordt gevormd door de oliehoudende kern, verhoudingsgewijs nu worden de hoeveelheden schil en kern bij kleine boonen ongunstiger ${ }^{1}$ ).

Gebruikers verlangen in de eerste plaats, dat de boonen gezond en goed gedroogd, voorts dat zij niet te oud zijn. De behandeling bij het oogsten draagt namelijk veel tot de kwaliteit bij, beschadigingen b.v. wreken zich in de hoedanigheid van de olie. Daartoe dient allereerst de bepaling van het zuurgetal en wat die grootheid aangaat verschillen de monsters van de Bovenwindsche eilanden niet van de monsters van andere herkomst. De verzorging van de boonen was dus goed geweest.

1) L. Adriaens, Le ricin au Congo Belge, 94 (Brussel 1938). 
Het oliegehalte (van de ongeschilde boonen) is lager dan dat van de boonen van andere herkomst, hetgeen een nadeelige factor genoemd moet worden; hierbij spelen ook de kleine afmetingen der boonen een rol. Als gunstige factor staat daartegenover, dat het acetylgetal van de olie hoog is. Wij hebben juist die grootheid nagegaan, in verband met een nieuwe toepassing voor ricinus-olie, die destijds zeer de aandacht trok, namelijk de omzetting van de van origine niet-drogende olie in een onverzadigde, d.w.z. juist weldrogende olie, van het type Chineesche houtolie ${ }^{1}$ ). Het Nederlandsche merk Synouryn en de buitenlandsche merken Isoline, Diënol en Triënol zijn alle handelsnamen voor kunstmatige drogende oliën, bereid uit ricinus-olie. Naar fabrikanten ons mededeelden, komt vooral vrijwel kleurlooze olie, met zoo hoog mogelijk acetylgetal voor die omzetting in aanmerking, hetgeen dus voor ons aanleiding was de monsters van de Bovenwindsche eilanden ook in die richting te onderzoeken. Het resultaat is in elk geval niet ongunstig.

ONDERZOEK VAN RICINUSBOONEN VAN DE BOVENWINDSCHE EILANDEN

\begin{tabular}{|c|c|c|c|c|c|}
\hline $\begin{array}{l}\text { H.M. } \\
\text { No. }\end{array}$ & Omschrijving & $\left|\begin{array}{c}1000 \\
\text { korrel } \\
\text { ge- } \\
\text { wicht }\end{array}\right|$ & olie & $\begin{array}{l}\text { zuur- } \\
\text { getal } \\
\mathrm{v} / \mathrm{d} \\
\text { olie } \\
\end{array}$ & $\begin{array}{l}\text { acetyl- } \\
\text { getal } \\
\mathrm{v} / \mathrm{d} \\
\text { olie } \\
\end{array}$ \\
\hline $97-5$ & Gouvernement Curaçao & $|123 \mathrm{~g}|$ & - & - & - \\
\hline $4565-1$ & $\begin{array}{l}\text { Bovenwindsche eilanden, in } \\
\text { het wild groeiend }\end{array}$ & & $44.8 \%$ & 2.65 & 145.9 \\
\hline $4565-3$ & $\begin{array}{l}\text { Bovenwindsche eilanden, van } \\
\text { planten met takken en blade- } \\
\text { ren, die niet rood gekleurd } \\
\text { zijn }\end{array}$ & 142 & $44.2 \%$ & 2.5 & 157.4 \\
\hline $4565-4$ & $\begin{array}{l}\text { Bovenwindsche eilanden, van } \\
\text { planten met een duidelijke } \\
\text { roode verkleuring op takken } \\
\text { en bladeren }\end{array}$ & 113 & $44.3 \%$ & 2.7 & 151.1 \\
\hline $4565-2$ & olie bereid op St. Eustatius & - & - & 7.6 & 147.4 \\
\hline 4421 & $\begin{array}{l}\text { Suriname,Landbouwproefsta- } \\
\text { tion }\end{array}$ & 675 & $48.5 \%$ & 5.4 & 142.9 \\
\hline $4567-7$ & Brazilië, uit den handel & 370 & - & - & 146.9 \\
\hline$-v$ & & 234 & $45.3^{c}$ & 2.1 & 150.9 \\
\hline 2371 & Marokko, Marrakech & 522 & $47.2 \%$ & 1.6 & 147.1 \\
\hline
\end{tabular}

1) Verg. Inlichtingen en Onderzoekingen van de Afdeeling Handelsmuse um in 1939, 49 (Meded. Afd. Handelsmuseum 21). 
Een afzonderlijke bespreking vraagt nog het monster olie, dat op St. Eustatius was bereid. Zorgvuldig is de winning blijkbaar niet geschied, want het zuurgetal is te hoog voor de verschillende toepassingen (b.v. medicinale olie - de bekende wonder-olie ten hoogste $4^{1}$ ), smeerolie voor vliegtuigmotoren ten hoogste $3^{2}$ ) enz.).

Tot zoover over de uit Willemstad ing zonden monsters. In onze adviezen moesten wij er op wijzèn, dat blijkbaar de op de Bovenwindsche eilanden aanwezige typet yan Ricinus communis gekenmerkt zijn door zeer kleine boonen of zaden, met in verband daarmede niet het hoogste oliegehalte. In vroeger jaren moet dat wel eens anders zijn geweest; althans vinden wij voor St. Eustatius vermeld ${ }^{3}$ ), dat daar in 1905 voorkwam een variëteit met bijzonder groote boonen, wit met roode vlekken gekleurd en met een groofe zaadproductie.

Het blijkt' mogelijk de boonen in goede hoedanigheid af te leveren. Zoolang door de bevolking slechts ingezameld kan worden van de in het wild groeiende planten en derhalve het kwantum wisselvallig is, verdient het aanbeveling de boonen niet zelf op olie te verwerken, maar deze terstond te exporteeren. Eerst indien als gevolg van weder in cultuur nemen op eén grootere en geregelde productie gerekend kan worden, zou wellicht bereiding van de olie ter plaatse in overweging genomen mogen worden. De daarbij overblijvende perskoek kan weliswaar wegens de aanwezigheid van sporen giftige stoffen niet zonder meer voor veevoeder worden gebruikt, maar heeft wegens haar betrekkelijken rijkdom aan stikstofhoudende verbindingen (5 tot $6 \%$ stikstof) wel waarde als meststof. Voor de eilanden in kwestie, waar kunstmest ingevoerd moet worden, ${ }^{4}$ zou dus toepassing van de perskoek ter plaatse voor de hand liggen.

Amsterdam, Juni 1944.

1) Nederl. Pharmacopee Ed. V 1926, 330.

2) F. H. van Leent, Analyse en warenkennis der voornaamste vette lichamen, 198 (Amsterdam 1934).

3) Bull. Kol. Museum Haarlem 34, 121 (1906).

4) Van de Benedenw. Eilanden ? Van elders werd in 1938 (laatste Verslag) geen kunstmest geïmporteerd, Redactie De West-Ind. Gids. 